\title{
Electrochemical Detection of Lipophilic Antioxidants with High Sensitivity at
}

\section{Boron-Doped Diamond Electrode}

Takeshi Kondo ${ }^{\text {a,b, }, 1}$, Kazuya Sakai ${ }^{\text {a }}$, Takeshi Watanabe ${ }^{\mathrm{c}}$, Yasuaki Einaga ${ }^{\mathrm{c}, \mathrm{d}}$, Makoto Yuasa $^{\mathrm{a}, \mathrm{b}}$

${ }^{\mathrm{a}}$ Department of Pure and Applied Chemistry, Faculty of Science and Technology, Tokyo

University of Science, 2641 Yamazaki, Noda, Chiba 278-8510, Japan

${ }^{\mathrm{b}}$ Research Institute for Science and Technology, Tokyo University of Science, 2641

Yamazaki, Noda, Chiba 278-8510, Japan

${ }^{\mathrm{c}}$ Department of Chemistry, Faculty of Science and Technology, Keio University, 3-14-1

Hiyoshi, Yokohama 223-8522, Japan

d JST,CREST, 3-14-1 Hiyoshi, Yokohama 223-8522, Japan

*Corresponding author. Tel. +81 471241501.

E-mail address: t-kondo@rs.noda.tus.ac.jp

${ }^{1}$ ISE member

(C) 2007. This manuscript version is made available under the Elsevier user license http://www.elsevier.com/open-access/userlicense/1.0/ 


\section{Abstract}

The electrochemical detection of lipophilic antioxidants, $\alpha$-tocopherol (vitamin

$\mathrm{E}, \mathrm{VE}$ ) and ubiquinone (coenzyme $\mathrm{Q}_{10}, \mathrm{CoQ}_{10}$ ), in methanol and in methanol/hexane mixture solutions, respectively, at boron-doped diamond (BDD) electrodes was investigated by cyclic voltammetry (CV) and flow-injection electrochemical measurements. $\mathrm{CV}$ measurements revealed that the overpotential for electrochemical reaction of $\mathrm{VE}$ and $\mathrm{CoQ}_{10}$ was larger at an oxidized $\mathrm{BDD}$ electrode surface than at that of a hydrogenated BDD (H-BDD) electrode. The slope of the CV calibration curve used to determine the $\mathrm{VE}$ and $\mathrm{CoQ}_{10}$ concentrations was larger at a glassy carbon (GC) electrode than at the H-BDD electrode; however, the signal-to-background ratio was larger at the H-BDD electrode than at the GC electrode, due to the low background feature of the H-BDD electrode. The limit of detection (LOD), defined by a signal-to-noise ratio of three for flow-injection electrochemical detection, was much smaller at the H-BDD electrode (VE: $41 \mathrm{nM}$ and $\left.\mathrm{CoQ}_{10}: 17 \mathrm{nM}\right)$ than at the $\mathrm{GC}$ electrode (VE: $263 \mathrm{nM}$ and $\mathrm{CoQ}_{10}: 71 \mathrm{nM}$ ). These results confirm that the H-BDD electrode is reliable for the electrochemical detection of lipophilic antioxidants, especially at low concentrations. 
Keywords: boron-doped diamond electrodes; electroanalysis; antioxidants;

$\alpha$-tocopherol; ubiquinone 


\section{Introduction}

Lipophilic antioxidants (Fig. 1) such as $\alpha$-tocopherol (vitamin E, VE), ubiquinone (coenzyme $\mathrm{Q}_{10}, \mathrm{CoQ}_{10}$ ), and carotenoids are essential micronutrients used to protect humans against diseases related to oxidative stress, including cardiovascular disease, cancer, cataracts, and age-related problems [1, 2]. For example, VE can prevent living cell membranes from decomposing and turning by reacting with reactive oxygen species and lipid peroxide radicals [3]. The reduced form of $\mathrm{CoQ}_{10}$, ubiquinol $\left(\mathrm{CoQ}_{10} \mathrm{H}_{2}\right)$, coexists with $\mathrm{CoQ}_{10}$ and is the predominant form in tissues. Ubiquinol is also an important lipophilic antioxidant that is present in inner mitochondrial membranes, which can regenerate VE from its oxidative form ( $\alpha$-tocopheroxyl radical) [4-6]. The $\mathrm{CoQ}_{10} / \mathrm{CoQ}_{10} \mathrm{H}_{2}$ system also plays an important role in electron and proton transport in the mitochondrial respiratory chain [6]. The reduced level of antioxidants in plasma has been reported to be associated with numerous chronic diseases; therefore, determination of these antioxidants in physiological fluids should be an important subject in analytical chemistry. Besides clinical applications, reliable determination of these antioxidant concentrations in foods, cosmetics, dietary supplements could be beneficial in related industrial fields [7]. VE and $\mathrm{CoQ}_{10}$ are electroactive compounds that can be analyzed by electrochemical techniques. The phenolic group of VE can be 
oxidized at conventional glassy carbon (GC) electrodes[8], and the voltammetric oxidation peak can be used for the determination. Modified electrodes, e.g. polypyrrole-modified platinum electrode[1], carbon nanotube/DNA paste electrode[9] and multi-walled carbon nanotube-modified graphite electrode[10], as well as platinum microelectode[11] were also useful for sensitive electrochemical detection of VE. The $\mathrm{CoQ}_{10} / \mathrm{CoQ}_{10} \mathrm{H}_{2}$ redox system is based on the redox reaction of the quinone group, showing a well-defined redox peak pair at moderate potential region in cyclic voltammetry $(\mathrm{CV})$. Mikchalkiewicz demonstrated the determination of $\mathrm{CoQ}_{10}$ in acetic acid/acetonitrile solution from the cathodic peak current of differential pulse voltammetry (DPV) curves with a linearity range of $0.12-1.0 \mathrm{mM}$ and a limit of detection (LOD) of $0.014 \mathrm{mM}[6]$. More practically, high performance liquid chromatography with an electrochemical detector (HPLC-EC) system should be useful for determination of $\mathrm{VE}$ and $\mathrm{CoQ}_{10}$ with high sensitivity and selectively [7, 12-17]. If the analytical accuracy for such compounds, such as the $\mathrm{CoQ}_{10} / \mathrm{CoQ}_{10} \mathrm{H}_{2}$ ratio measured with a HPLC-EC system, could be improved, then it would also be useful for research into the relationship between oxidative stress and initial diagnoses $[14,15,17,18]$.

In the present study, the electrochemical detection of $\mathrm{VE}$ and $\mathrm{CoQ}_{10}$ lipophilic antioxidants at boron-doped diamond (BDD) electrodes was investigated. BDD 
electrodes exhibit a wide potential window and low background current, and therefore have potential application to highly sensitive electroanalysis [19-27]. Although there are many reports on electroanalysis at BDD electrodes in aqueous media, there have been few reports for non-aqueous media, which should be also important to be developed. Radovan [28] and Martins [29] reported on sensitive detection of parabens in hydro-alcoholic and water-acetonitrile solutions, respectively. Medeiros reported on voltammetric detection of phenolic antioxidants in aqueous-ethanolic solutions[30]. Zhang investigated sensitive electrochemical detection of 3,6-dihydroxyphenanthrene in methanol solution, based on the lower background current at BDD electrode than at GC electrode[31]. We performed $\mathrm{CV}$ of $\mathrm{VE}$ and $\mathrm{CoQ}_{10}$ at hydrogenated and oxidized BDD electrodes (H-BDD and O-BDD) to investigate the electrochemical reaction properties. Furthermore, the BDD electrodes were applied to a flow-injection electrochemical measurement to investigate the determination of the lipophilic antioxidants at HPLC-EC systems.

\section{Experimental}

BDD electrodes were obtained by deposition of a polycrystalline BDD thin 
film on a silicon wafer substrate using the microwave plasma-assisted chemical vapor deposition (MPCVD) method. The detailed conditions have been described in our previous report [32]. Hydrogen plasma treatment using MPCVD apparatus with a microwave power of $500 \mathrm{~W}$ and a total pressure of 25 Torr at $800{ }^{\circ} \mathrm{C}$ for 5 min allowed hydrogenation of the BDD electrode surface. Surface oxidation of the BDD electrode was performed with a UV/ozone photo surface processor (UVE-110-1H, Sen Light Corporation) equipped with a low-pressure mercury lamp (185 and $254 \mathrm{~nm}$ ). The lamp to sample distance was $80 \mathrm{~mm}$. The $\mathrm{O} / \mathrm{C}$ atomic ratio of the modified BDD surface was estimated using X-ray photoelectron spectroscopy (XPS, Axis Nova, Kratos).

$\alpha$-Tocopherol (or vitamin E, VE) and ubiquinone (or coenzyme $\mathrm{Q}_{10}, \mathrm{CoQ}_{10}$ ) were purchased from Wako Pure Chemical Industries and were used as received. For CV, $50 \mathrm{mM}$ of sodium perchlorate in methanol was used as an electrolyte solution for VE.

On the other hand, we used a mixture of $2 \mathrm{~mL}$ sulfuric acid (98\%)/230 mL methanol/70 $\mathrm{mL}$ hexane for $\mathrm{CoQ}_{10}$ because hexane can dissolve $\mathrm{CoQ}_{10}$ well. $\mathrm{CV}$ was performed using a three-electrode electrochemical cell with platinum wire and $\mathrm{Ag} / \mathrm{Ag}^{+}$(BAS) as counter and reference electrodes, respectively, and a potentiostat (HZ-5000, Hokuto Denko). The working electrode area was regulated by a Viton O-ring to be $0.07 \mathrm{~cm}^{2}$ (3 $\mathrm{mm}$ in diameter). 
Flow-injection electrochemical measurements were conducted using a liquid pump (PU-712, GL Science) and an electrochemical detector (ED-703 pulse, GL Science) installed with $\mathrm{GC}$ or BDD electrodes. A Ag/ $\mathrm{AgCl}$ electode was employed for the reference electrode. The working electrode area was set to $0.15 \mathrm{~cm}^{2}$ using a silicone rubber gasket. The mobile phases for $\mathrm{VE}$ and $\mathrm{CoQ}_{10}$ were $50 \mathrm{mM}$ sodium perchlorate in methanol and $50 \mathrm{mM}$ sodium perchlorate in methanol/hexane $(76.7 / 23.3, \mathrm{v} / \mathrm{v})$, respectively. We chose sodium perchlorate as a neutral electrolyte to minimize any damage to the instruments. A $10 \mu \mathrm{L}$ aliquot of the electrolyte containing VE or $\mathrm{CoQ}_{10}$ was injected for the measurement. For the flow-injection electrochemical measurement of $\mathrm{CoQ}_{10}$, a quinone-derivative reduction column (No. 21211, Shiseido), where $\mathrm{CoQ}_{10}$ is reduced to $\mathrm{CoQ}_{10} \mathrm{H}_{2}$, was connected just before the electrochemical detector, and the oxidation current of $\mathrm{CoQ}_{10} \mathrm{H}_{2}$ was detected. The flow rate of the mobile phase was $1 \mathrm{~mL}$ $\min ^{-1}$.

\section{Results and Discussion}

\subsection{Surface modification of BDD}

Surface oxidation of the BDD electrode by UV/ozone treatment was investigated. Figures $2 \mathrm{a}$ and $2 \mathrm{~b}$ show XPS spectra of the H-BDD surface and that 
treated with UV/ozone for $60 \mathrm{~min}$, respectively. The intensity of the $\mathrm{O} 1 \mathrm{~s}$ peak $(530 \mathrm{eV})$ in the H-BDD spectrum was rather small, whereas that for the treated surface was significantly increased. The $\mathrm{O} / \mathrm{C}$ atomic ratios estimated by XPS quantitative analysis were 0.014 and 0.12 for the H-BDD and UV/ozone-treated BDD electrodes, respectively. The $\mathrm{O} / \mathrm{C}$ ratio is plotted as a function of $\mathrm{UV} /$ ozone treatment time in Fig. 2c. The $\mathrm{O} / \mathrm{C}$ ratio increased significantly within several minutes and became almost saturated at $30 \mathrm{~min}$ or longer, which is similar to that previously reported [33]. The results indicate that the surface oxygen content can be controlled according to the UV/ozone treatment time. The $\mathrm{O} / \mathrm{C}$ ratio became almost saturated by treatment for 30 min or longer; therefore, BDD samples treated by UV/ozone for $30 \mathrm{~min}$ were used as oxidized BDD electrodes (O-BDD) unless otherwise specified. The contact angles of water droplets on the $\mathrm{H}$ - and O-BDD surfaces were 102 and $32^{\circ}$, respectively, which is consistent with that previously reported [34].

\section{2. $\mathrm{CV}$ of $\mathrm{VE}$}

Figure 3 shows CVs for VE in $50 \mathrm{mM}$ sodium perchlorate/methanol at $\mathrm{H}$ - and O-BDD electrodes. The CVs have an anodic peak and indicate that no reduction reaction occurred during the cathodic scan. The mechanism of the electrochemical 
oxidation of VE is complicated due to the variation of oxidized forms of the phenolic group depending on the solvent, electrolyte and the amount of water contained[3, 35-37]. According to literature, the anodic peak should be based on the following reaction[3, 37]:

$$
\alpha-\mathrm{TOH}(\mathrm{VE}) \rightarrow \alpha-\mathrm{TO}^{+}+\mathrm{H}^{+}+2 \mathrm{e}^{-}
$$

In the presence of water as an impurity in the organic solvent, the oxidation product of $\mathrm{VE}, \alpha-\mathrm{TO}^{+}$is subjected to subsequent reaction with water to form products, which can not be reduced electrochemically back to VE[37]. An anodic peak was observed for VE at the $\mathrm{H}-\mathrm{BDD}$ electrode at $+0.4 \mathrm{~V}$ vs. $\mathrm{Ag} / \mathrm{Ag}^{+}$, and the peak potential had a positive shift with increase in the UV/ozone treatment time. At the O-BDD treated with UV/ozone for 30 min, the anodic peak was obscure, due to overlap with the oxygen evolution reaction current. Thus, the overpotential for VE oxidation was dependent on the degree of surface oxidation of the BDD electrode. One possible reason for this behavior may be the hydrophobic interaction between VE and the BDD surface, because VE is a hydrophobic/oleophilic molecule with a long alkyl chain. The hydrogen-terminated diamond surface is also hydrophobic/oleophilic, due to the $\mathrm{C}-\mathrm{H}$ functionality with a small dipole moment. Thus, the interaction between VE molecules and the electrode surface should be more attractive at H-BDD than at O-BDD electrodes. Another 
possible reason could be the electrostatic interaction between the phenolic $\mathrm{OH}$ group of the VE molecule and the electrode surface functionalities. The phenolic $\mathrm{OH}$ group is the electroactive part of the VE molecule and the $\mathrm{C}-\mathrm{OH}$ group has a dipole with $\delta^{-}$ directing outward. Therefore, electrostatic repulsion between $\mathrm{C}-\mathrm{OH}$ groups and the oxygen-containing groups at the O-BDD electrode surface may be responsible for slow electron transfer resulting in a large overpotential $[34,38]$. The small overpotential for VE oxidation revealed that the hydrogen-terminated surface is suitable for the detection of $\mathrm{VE}$ at BDD electrodes. The anodic peak current density at the H-BDD electrode was found to increase linearly to square root of potential sweep rate from 10 to $100 \mathrm{mV} \mathrm{s}^{-1}$ and the peak potential shift to the positive direction with potential sweep rate (not shown), which is typical of an irreversible and diffusion-controlling process [39]. Therefore, VE should not be adsorbed strongly on the H-BDD electrode surface. Figures $4 \mathrm{a}$ and $4 \mathrm{~b}$ show CVs for VE at glassy carbon (GC) and H-BDD electrodes with various VE concentrations. The peak current density increased linearly with the VE concentration (Fig. 4c), which confirmed that these electrodes are useful for the electrochemical determination of VE concentration. The slope of the calibration curve was larger for the GC electrode than the H-BDD electrode; however, the background current was much smaller for H-BDD $\left(2.8 \mu \mathrm{A} \mathrm{cm}{ }^{-2}\right)$ than $\mathrm{GC}\left(14.8 \mu \mathrm{A} \mathrm{cm}{ }^{-2}\right)$, which 
resulted in a larger signal-to-background $(\mathrm{S} / \mathrm{B})$ ratio at the H-BDD electrode than the GC electrode. For example, the signal current density for $1 \mathrm{mM} \mathrm{VE}$ at the H-BDD and GC electrodes was 282 and $408 \mu \mathrm{A} \mathrm{cm}^{-2}$ (the former value was calculated from the calibration curve in Fig. 4c), thus the S/B ratio was 101 and 28, respectively. Such a large $\mathrm{S} / \mathrm{B}$ ratio for electrochemical detection at $\mathrm{BDD}$ electrodes is similar to those in aqueous electrolytes (e.g., the detection of histamine, serotonin [40] and oxalic acid [38]). Therefore, the BDD electrode is also useful for highly sensitive electrochemical detection in non-aqueous media.

\section{3. $\mathrm{CV}$ of $\mathrm{CoQ}_{10}$}

Figure 5 shows $\mathrm{CVs}$ for $\mathrm{CoQ}_{10}$ at $\mathrm{GC}$ and $\mathrm{H}-\mathrm{BDD}$ electrodes. $\mathrm{CoQ}_{10}$ is in the oxidized state; therefore, the $\mathrm{CV}$ was recorded from the rest potential to a cathodic switching potential more negative than the cathodic peak potential, followed by an anodic scan.

$$
\begin{aligned}
& \mathrm{CoQ}_{10}+2 \mathrm{H}^{+}+2 \mathrm{e}^{-} \rightarrow \mathrm{CoQ}_{10} \mathrm{H}_{2} \quad \text { (cathodic reaction) } \\
& \mathrm{CoQ}_{10} \mathrm{H}_{2} \rightarrow \mathrm{CoQ}_{10}+2 \mathrm{H}^{+}+2 \mathrm{e}^{-} \quad \text { (anodic reaction) }
\end{aligned}
$$

The feature that the cathodic peak current density was larger than the anodic one was consistent with the result on Michalkievicz's report[41]. According to the report, it was 
concluded that this feature is due to unstable semiubiquinone radical $\left(\mathrm{CoQ}_{10} \mathrm{H}^{\circ}\right)$, which is a primary product of one-electron one-proton reduction of $\mathrm{CoQ}_{10}$. This radical can undergo an electrochemical disproportionation causing a decrease of the anodic peak in comparison to the cathodic one. At the O-BDD electrode, the cathodic peak was often obscured by overlap with the cathodic current for decomposition of the solvent, due to a large overpotential (result not shown). This behavior was similar to the CV for VE at BDD electrodes. $\mathrm{CoQ}_{10}$ is a hydrophobic/oleophilic molecule with a long isoprene chain. Hydrophobic interaction between the isoprene chain and the $\mathrm{C}-\mathrm{H}$ groups at the H-BDD surface can facilitate fast electron transfer with small overpotential. However, the electrostatic repulsion between the $\mathrm{C}=\mathrm{O}$ group of the quinone part of $\mathrm{CoQ}_{10}$ and the oxygen-containing functional group at the O-BDD surface can also result in a large overpotential. The anodic and cathodic peak current density increased linearly to $v^{1 / 2}$, which indicates a diffusion-controlling $\mathrm{CV}$ process (Fig. 5b, inset). The anodic and cathodic peak current density was directly proportional to the $\mathrm{CoQ}_{10}$ concentration, which indicates that the H-BDD electrode can also be used for the electrochemical determination of $\mathrm{CoQ}_{10}$ concentration (Fig. 6).

3.4. VE detection with a flow-injection system 
The detection of $\mathrm{VE}$ and $\mathrm{CoQ}_{10}$ was estimated using an FIA-EC system to investigate the effectiveness of BDD electrodes for the electrochemical detection of lipophilic antioxidants with HPLC. Figure 7 shows hydrodynamic voltammograms (HDVs) for VE detection at GC and H-BDD electrodes. The sample was injected three times at each single electrode potential. The current just before the peak was defined as the background current for calculation of the signal current by subtracting the background current from the peak current. The signal current at the O-BDD electrode was very small (results not shown), due to the large overpotential of VE oxidation, which was consistent with the result of CV. The background current was smaller at the H-BDD electrode than at the GC electrode. Consequently, the S/B ratio was three times larger at the H-BDD electrode than at the GC electrode (Fig. 7b). Calibration curves for VE detection with a concentration range from 0.5 to $100 \mu \mathrm{M}$ were created using optimal potentials of +0.35 and $+0.6 \mathrm{~V}$ vs. $\mathrm{Ag} / \mathrm{AgCl}$ at $\mathrm{GC}$ and $\mathrm{H}-\mathrm{BDD}$ electrodes, respectively, where the largest S/B ratios were obtained (not shown). The curves have good linearity

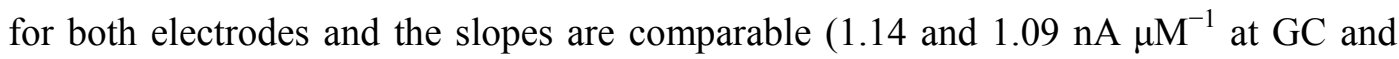
H-BDD electrodes, respectively). However, the current noise was much lower at the H-BDD electrode than at the GC electrode. Figures $8 \mathrm{a}$ and $8 \mathrm{~b}$ show the amperometric current for $0.5-3.5 \mu \mathrm{M}$ VE sample injection. While the signal for $0.5 \mu \mathrm{M}$ was 
ambiguous due to noise at the GC electrode (Fig. 8a), the signal was clear at the H-BDD electrode due to the low noise (Fig. 8b). This difference in noise levels is based on the background current level. The noise evaluated by the variation of current during a unit time segment $(1.2 \mathrm{~s})$, defined by ten times the full width at half maximum of a single noise peak, was 0.100 and $0.015 \mathrm{nA}$ for the GC and the H-BDD electrodes, respectively (Figs. 8c and 8d). The limit of detection (LOD) and limit of quantification (LOQ), defined as $\mathrm{S} / \mathrm{N}=3$ and 10 , respectively, was calculated from the calibration curves to be 263 and $877 \mathrm{nM}$ for the GC electrode and 41 and $138 \mathrm{nM}$ for the H-BDD electrodes, respectively. Hassan demonstrated the determination of VE in pharmaceuticals by DPV technique using a GC electrode[8]. The LOD of this system was found to be $0.0136 \mathrm{mg}$ $\mathrm{L}^{-1}$ (or $31.6 \mathrm{nM}$ ), which was sufficiently low for the determination (ca. $2 \mathrm{mg} \mathrm{L}^{-1}$ or 4.6 $\mu \mathrm{M})$. VE in human plasma was determined by Lee by using an HPLC system with a fluorescence detector (LOD: $0.004 \mathrm{mg} \mathrm{L}^{-1}$ or $9 \mathrm{nM}$ ) to be ca. $14 \mathrm{mg} \mathrm{L}^{-1}$ (or 32.5 $\mu \mathrm{M})[42]$. Thus, the H-BDD electrode should have sufficiently high sensitivity for the electrochemical determination of VE from these samples with a flow system.

\section{5. $\mathrm{CoQ}_{10}$ detection with a flow-injection system}

The electrochemical detection of $\mathrm{CoQ}_{10}$ was also investigated with a 
flow-injection electrochemical system. The $\mathrm{CoQ}_{10} / \mathrm{CoQ}_{10} \mathrm{H}_{2}$ ratio can be used as an indicator for the estimation of oxidative stress in living bodies. To evaluate this ratio, a reduction column is placed after the separation column and the oxidation current of the reduced $\mathrm{CoQ}_{10}\left(\mathrm{CoQ}_{10} \mathrm{H}_{2}\right)$ is detected at the electrochemical detector. The maximum $\mathrm{S} / \mathrm{B}$ ratios for $50 \mu \mathrm{M} \mathrm{CoQ}_{10}$ detection in the HDVs for the GC and H-BDD electrodes were 37.8 and 20.4 at +0.3 and $+0.5 \mathrm{~V}$ vs. $\mathrm{Ag} / \mathrm{AgCl}$, respectively (Fig. 9). The GC electrode had a larger maximum S/B ratio than the $\mathrm{H}-\mathrm{BDD}$ electrode, because $\mathrm{CoQ}_{10} \mathrm{H}_{2}$ can be oxidized at less positive electrode potentials, where the background current was sufficiently low. At the optimal electrode potentials found from the HDV $(+0.3$ and +0.5 V vs. $\mathrm{Ag} / \mathrm{AgCl}$ for $\mathrm{GC}$ and $\mathrm{H}-\mathrm{BDD}$ electrodes, respectively), $\mathrm{CoQ}_{10}$ detection properties were investigated in the concentration range from 0.5 to $100 \mu \mathrm{M}$. Calibration curves were created from the average of three injections for a single sample and showed good linearity with slopes of 2.10 and $1.15 \mathrm{nA} \mu \mathrm{M}^{-1}$ for the GC and H-BDD electrodes, respectively (not shown). The noise for the GC and H-BDD electrodes was 0.05 and $0.0065 \mathrm{nA}$. The LODs $(\mathrm{S} / \mathrm{N}=3)$ and LOQ $(\mathrm{S} / \mathrm{N}=10)$ for the $\mathrm{GC}$ and $\mathrm{H}-\mathrm{BDD}$ electrodes were calculated to be 71 and $238 \mathrm{nM}$, and 17 and $57 \mathrm{nM}$, respectively. Thus, the H-BDD is useful for the detection of $\mathrm{CoQ}_{10}$ based on the extremely low noise level, while the signal itself is larger at the GC electrode than at the H-BDD electrode. 
Michalkiewicz demonstrated the determination of $\mathrm{CoQ}_{10}$ in pharmaceuticals by using DPV at a GC electrode[6]. The LOD was found to be $14 \mu \mathrm{M}$, which was low enough for the determination from the pharmaceutical samples containing $10-30 \mathrm{mg}$ of $\mathrm{CoQ}_{10}$. From Lee's report[42], $\mathrm{CoQ}_{10}$ and $\mathrm{CoQ}_{10} \mathrm{H}_{2}$ concentration in human plasma were determined to be 0.712 and $0.117 \mathrm{mg} \mathrm{L}^{-1}$ (827 and $136 \mathrm{nM}$ ), respectively. Since they are more than the LOQ, the electrochemical detection at H-BDD with the flow system would be applicable to the determination of $\mathrm{CoQ}_{10} / \mathrm{CoQ}_{10} \mathrm{H}_{2}$ in human plasma.

\section{Conclusions}

The electrochemical detection of VE and $\mathrm{CoQ}_{10}$ lipophilic antioxidants at BDD electrodes was investigated. CV results revealed the electron transfer for electrochemical reaction of these antioxidants was faster at H-BDD than O-BDD. This behavior is due to the hydrophobic interaction between the molecules and the H-BDD surface and the electrostatic repulsion between the electroactive part of the VE and $\mathrm{CoQ}_{10}$ molecules and the surface functionalities of O-BDD. The application of an H-BDD electrode as an electrochemical detector for HPLC systems used for VE and $\mathrm{CoQ}_{10}$ analysis was investigated using a flow-injection electrochemical system. The noise level was found to be much lower at the H-BDD electrode than at the GC 
electrode; therefore, the estimated LOD was much smaller at H-BDD (VE: $41 \mathrm{nM}$ and $\left.\mathrm{CoQ}_{10}: 17 \mathrm{nM}\right)$ than at GC (VE: $263 \mathrm{nM}$ and $\left.\mathrm{CoQ}_{10}: 71 \mathrm{nM}\right)$. Thus, the H-BDD electrode should be useful for sensitive electrochemical detection of these lipophilic antioxidants.

\section{Acknowledgment}

This work was supported by the Project to develop "innovative seed" of the Japan Science and Technology Agency (JST). 


\section{References}

[1] S.-G. Li, W.-T. Xue, H. Zhang, Electroanalysis, 18 (2006) 2337.

[2] K. Chong-Han, Crit. Rev. Food Sci. Nutr., 50 (2010) 931.

[3] R.D. Webster, Acc. Chem. Res., 40 (2007) 251.

[4] S. Michalkiewicz, Bioelectrochemistry, 82 (2011) 103.

[5] A.A. Franke, C.M. Morrison, J.L. Bakke, L.J. Custer, X. Li, R.V. Cooney, Free Rad. Biol. Med., 48 (2010) 1610.

[6] S. Michalkiewicz, Bioelectrochemistry, 73 (2008) 30.

[7] A. Kettawan, C. Kunthida, T. Takahashi, T. Kishi, J. Chikazawa, Y. Sakata, E. Yano,

K. Watabe, Y. Yamamoto, T. Okamoto, J. Clin. Biochem. Nutr., 41 (2007) 124.

[8] E.M. Hassan, E.F. Khamis, E.I. El-Kimary, M.A. Barary, Talanta, 74 (2008) 773.

[9] S.Y. Ly, J. Sci. Food Agric., 88 (2008) 1272.

[10] G. Ziyatdinova, M. Morozov, H. Budnikov, J. Solid State Electrochem., 16 (2012) 2441.

[11] S. Michalkiewicz, M. Tutaj, M. Kaczor, J. Malyszko, Electroanalysis, 14 (2002) 297.

[12] S.L. Molyneux, M. Lever, Clin. Chim. Acta, 358 (2005) 198.

[13] A. Galinier, A. Carrière, Y. Fernandez, A.M. Bessac, S. Caspar-Bauguil, B. Periquet, 
M. Comtat, J.P. Thouvenot, L. Casteilla, FEBS Lett., 578 (2004) 53.

[14] B.A. Barshop, J.A. Gangoiti, Mitochondrion, 7, Supplement (2007) S89.

[15] J. Ruiz-Jiménez, F. Priego-Capote, J.M. Mata-Granados, J.M. Quesada, M.D. Luque de Castro, J. Chromatogr. A, 1175 (2007) 242.

[16] M.-C. Bélanger, M.-É. Mirault, E. Dewailly, L. Berthiaume, P. Julien, Metabolism: clinical and experimental, 57 (2008) 927.

[17] M.V. Miles, P.H. Tang, L. Miles, P.E. Steele, M.J. Moye, P.S. Horn, Biomed. Chromatogr., 22 (2008) 1403.

[18] L. Miles, M.V. Miles, P.H. Tang, P.S. Horn, J.G. Quinlan, B. Wong, A. Wenisch, K.E. Bove, Clin. Chim. Acta, 360 (2005) 87.

[19] Diamond Electrochemistry, Elsevier-BKC, Tokyo, 2005.

[20] A. Fujishima, T.N. Rao, E. Popa, B.V. Sarada, I. Yagi, D.A. Tryk, J. Electroanal. Chem., 473 (1999) 179.

[21] T. Kondo, H. Sakamoto, T. Kato, M. Horitani, I. Shitanda, M. Itagaki, M. Yuasa, Electrochem. Commun., 13 (2011) 1546.

[22] T.N. Rao, I. Yagi, T. Miwa, D.A. Tryk, A. Fujishima, Anal. Chem., 71 (1999) 2506.

[23] J.W. Strojek, M.C. Granger, G.M. Swain, T. Dallas, M.W. Holtz, Anal. Chem., 68 (1996) 2031. 
[24] A. Suzuki, T.A. Ivandini, K. Yoshimi, A. Fujishima, G. Oyama, T. Nakazato, N. Hattori, S. Kitazawa, Y. Einaga, Anal. Chem., 79 (2007) 8608.

[25] G.M. Swain, R. Ramesham, Anal. Chem., 65 (1993) 345.

[26] Y. Einaga, J. Appl. Electrochem., 40 (2010) 1807.

[27] R.G. Compton, J.S. Foord, F. Marken, Electroanalysis, 15 (2003) 1349.

[28] C. Radovan, D. Cinghită, F. Manea, M. Mincea, C. Cofan, V. Ostafe, Sensors, 8 (2008) 4330.

[29] I. Martins, F.C. Carreira, L.S. Canaes, F.A. de Souza Campos Junior, L.M. da Silva Cruz, S. Rath, Talanta, 85 (2011) 1.

[30] R.A. Medeiros, R.C. Rocha-Filho, O. Fatibello-Filho, Food Chem., 123 (2010) 886.

[31] Y. Zhang, S. Asahina, M. Suzuki, S. Yoshihara, T. Shirakashi, Surf. Coat. Technol., 169-170 (2003) 303.

[32] T. Kondo, S. Aoshima, K. Honda, Y. Einaga, A. Fujishima, T. Kawai, J. Phys. Chem. C, 111 (2007) 12650.

[33] T. Kondo, S. Aoshima, K. Hirata, K. Honda, Y. Einaga, A. Fujishima, T. Kawai, Langmuir, 24 (2008) 7545.

[34] I. Yagi, H. Notsu, T. Kondo, D.A. Tryk, A. Fujishima, J. Electroanal. Chem., 473 
(1999) 173.

[35] J. Malyszko, M. Karbarz, J. Electroanal. Chem., 595 (2006) 136.

[36] L.L. Williams, R.D. Webster, J. Am. Chem. Soc., 126 (2004) 12441.

[37] Y.S. Tan, S. Chen, W.M. Hong, J.M. Kan, E.S.H. Kwek, S.Y. Lim, Z.H. Lim, M.E. Tessensohn, Y. Zhang, R.D. Webster, Phys. Chem. Chem. Phys., 13 (2011) 12745.

[38] T. Kondo, Y. Niwano, A. Tamura, T.A. Ivandini, Y. Einaga, D.A. Tryk, A. Fujishima, T. Kawai, Electroanalysis, 20 (2008) 1556.

[39] L.R.F. Allen J. Bard, Electrochemical Metods Fundamentals and Applications, Second Edition, John Wiley \& Sons, Inc., 2001.

[40] B.V. Sarada, T.N. Rao, D.A. Tryk, A. Fujishima, Anal. Chem., 72 (2000) 1632.

[41] S. Michalkiewicz, Bioelectrochemistry, 70 (2007) 495.

[42] B.L. Lee, C.N. Ong, J. Chromatogr. A, 1216 (2009) 3131. 


\section{Figure Captions}

Figure 1. Chemical structure of $\alpha$-tocopherol, ubiquinone and ubiquinol. Scheme of ubiquinone/ubiquinol redox couple is also illustrated.

Figure 2. XPS spectra of (a) H-BDD and (b) O-BDD fabricated by UV/ozone treatment for $60 \mathrm{~min}$. (c) $\mathrm{O} / \mathrm{C}$ atomic concentration ratio of O-BDD surface as a function of UV/ozone treatment time.

Figure 3. (a) $\mathrm{CVs}$ for $1.5 \mathrm{mM} \mathrm{VE}$ in $50 \mathrm{mM} \mathrm{NaClO} /$ methanol at $\mathrm{H}$-BDD and O-BDD electrodes with various UV/ozone treatment times, measured at a potential sweep rate of $50 \mathrm{mV} \mathrm{s}^{-1}$. (b) $\mathrm{CVs}$ of $1.5 \mathrm{mM} \mathrm{VE}$ in $50 \mathrm{mM} \mathrm{NaClO}_{4} /$ methanol at $\mathrm{H}-\mathrm{BDD}$ with various potential sweep rates $\left(10-100 \mathrm{mV} \mathrm{s}^{-1}\right)$. Inset in panel $\mathrm{b}$ shows the anodic peak current density $\left(i_{\mathrm{pa}}\right)$ as a function of the square root of the potential sweep rate $\left(v^{1 / 2}\right)$.

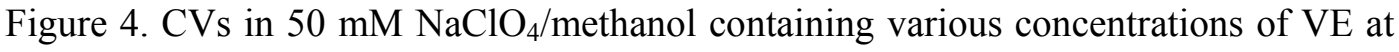

(a) GC and (b) H-BDD electrodes, measured at a potential sweep rate of $50 \mathrm{mV} \mathrm{s}^{-1}$. (c)

Plots of the anodic peak current density $\left(i_{\mathrm{pa}}\right)$ as a function of VE concentration from the data in panels a and $b$. 
Figure 5. CVs for $1 \mathrm{mM} \mathrm{CoQ} 10$ in $\mathrm{H}_{2} \mathrm{SO}_{4} /$ hexane/methanol at (a) GC and (b) H-BDD electrodes with various potential sweep rates $\left(5-100 \mathrm{mV} \mathrm{s}^{-1}\right)$. Inset in panel $\mathrm{b}$ shows the anodic and cathodic peak current density $\left(i_{\mathrm{pa}}\right.$ and $\left.i_{\mathrm{pc}}\right)$ as a function of the square root of the potential sweep rate $\left(v^{1 / 2}\right)$.

Figure 6. CVs for various concentrations of $\mathrm{CoQ}_{10}$ in $\mathrm{H}_{2} \mathrm{SO}_{4} /$ hexane/methanol at (a) $\mathrm{GC}$ and (b) H-BDD electrodes. The potential sweep rate was $50 \mathrm{mV} \mathrm{s}^{-1}$. (c) Plots of the anodic peak current density $\left(i_{\mathrm{pa}}\right)$ as a function of VE concentration from the data in panels a and $b$.

Figure 7. HDVs for the detection of $40 \mu \mathrm{M}$ VE using GC and H-BDD electrodes with a flow-injection electrochemical system. (a) Signal and background current as a function of electrode potential. (b) S/B ratio as a function of electrode potential.

Figure 8. Flow-injection amperograms for low concentration VE samples at (a) GC and (b) H-BDD electrodes (electrode potentials were +0.35 and $+0.6 \mathrm{~V}$ vs. $\mathrm{Ag} / \mathrm{AgCl}$ for $\mathrm{GC}$ and H-BDD electrodes, respectively). Noise in the amperograms at a baseline region 
within one unit segment time (12 s) for (c) GC and (d) H-BDD electrodes.

Figure 9. HDVs for the detection of $50 \mu \mathrm{M} \mathrm{CoQ}_{10}$ using GC and H-BDD electrodes with a flow-injection electrochemical system. (a) Signal and background current as a function of electrode potential. (b) S/B ratio as a function of the electrode potential. 


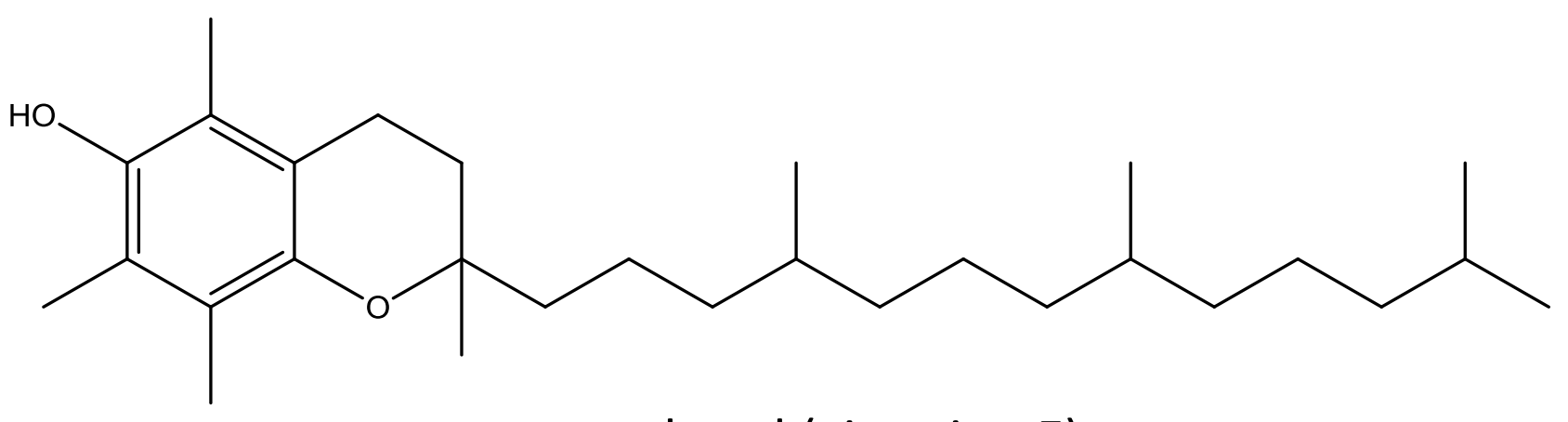

$\alpha$-tocopherol (vitamine E)

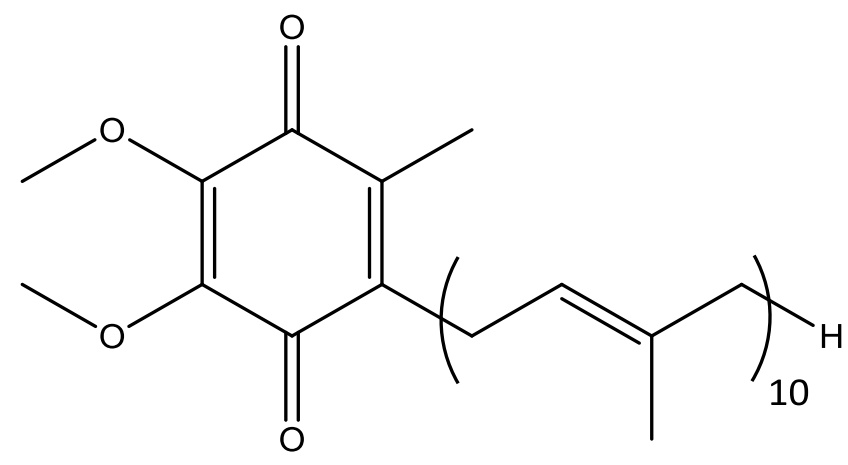

ubiquinone (coenzyme $\mathrm{Q}_{10}$ )

$$
\begin{aligned}
& \stackrel{+2 \mathrm{H}^{+}+2 \mathrm{e}^{-}}{\longrightarrow} \\
& \stackrel{2 \mathrm{H}^{+}-2 \mathrm{e}^{-}}{\longrightarrow}
\end{aligned}
$$




\section{T. Kondo et al., Figure 2}
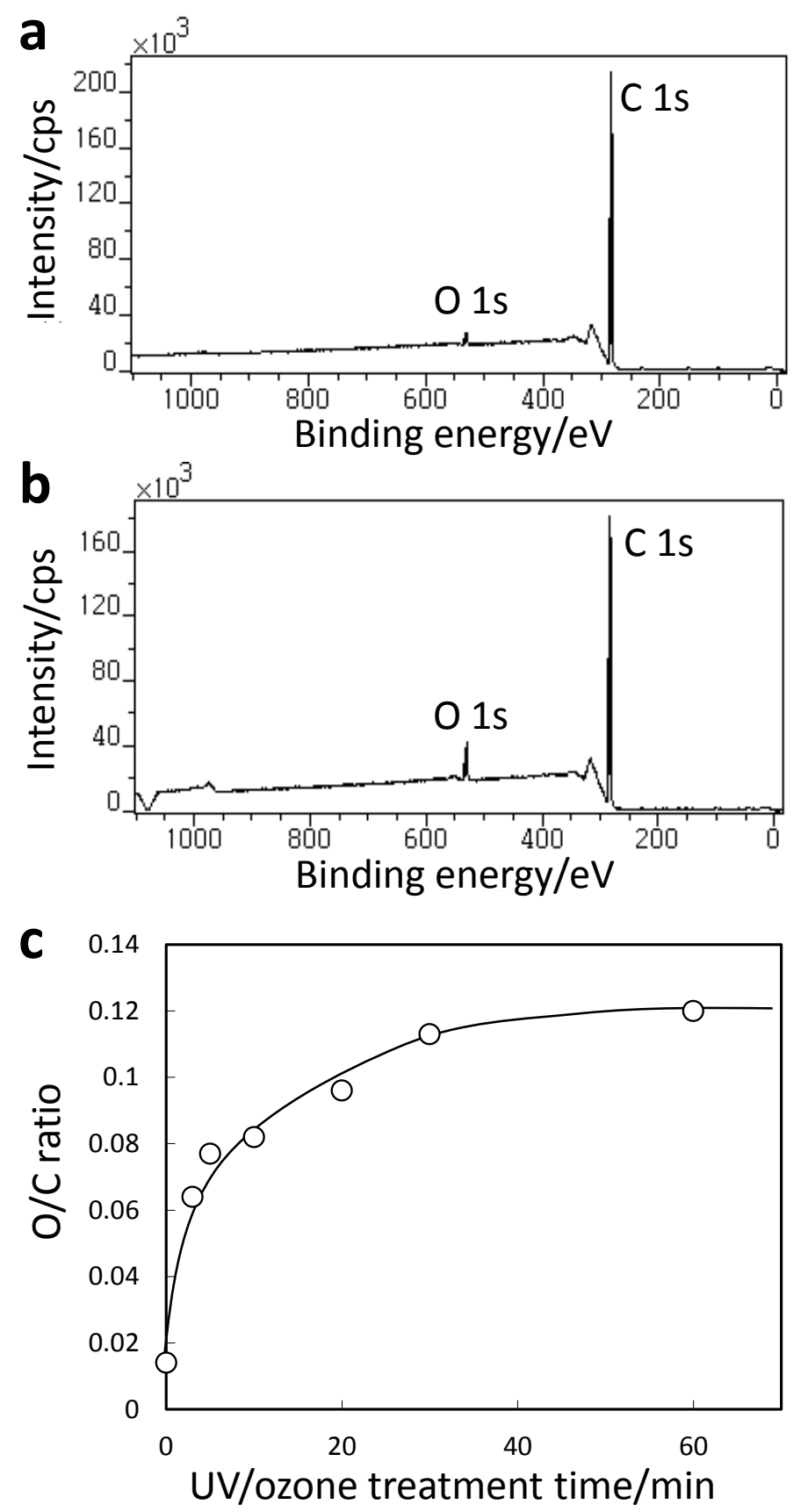


\section{T. Kondo et al., Figure 3}

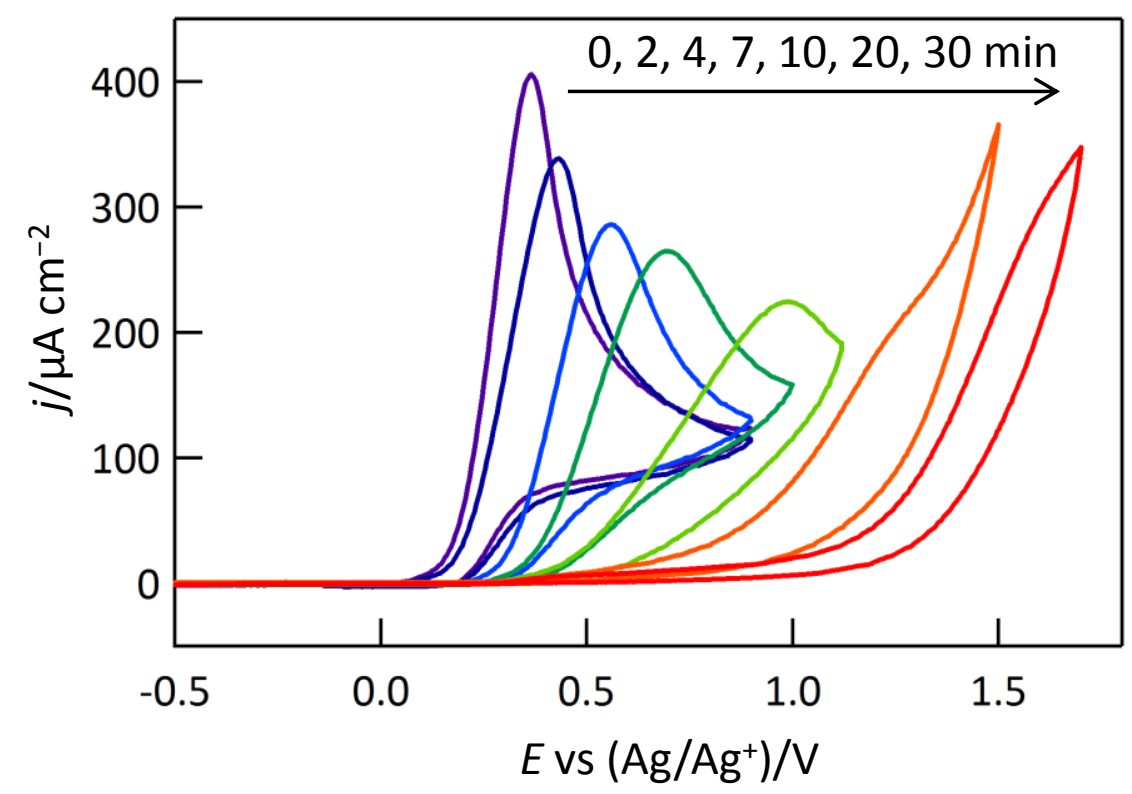




\section{T. Kondo et al., Figure 4}
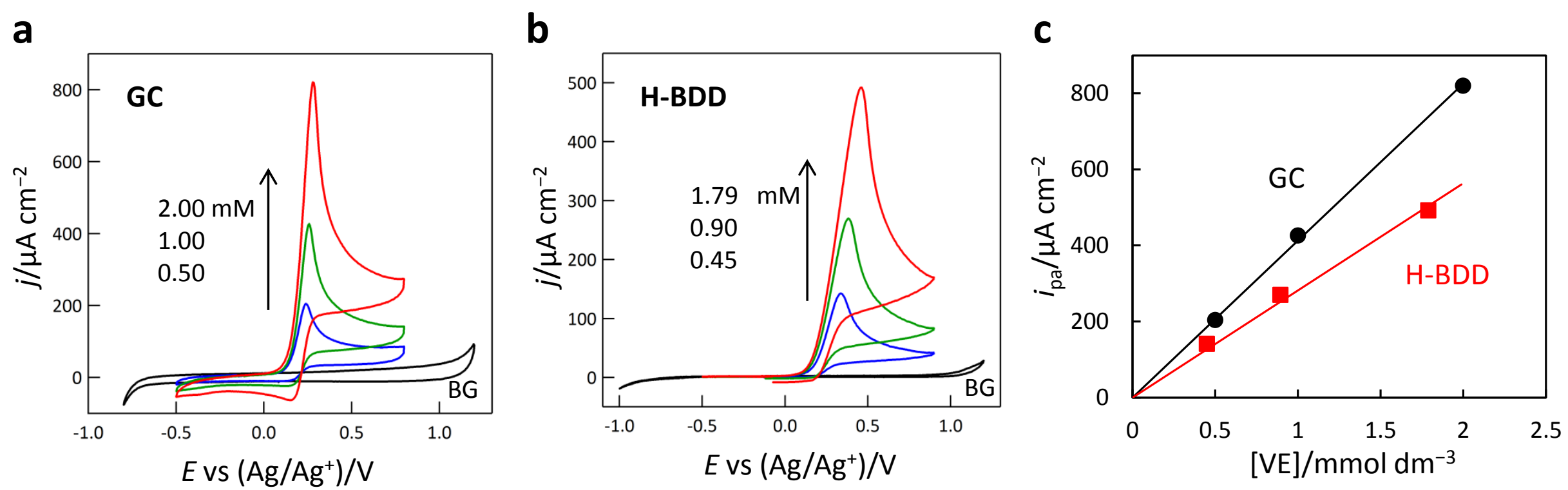


\section{T. Kondo et al., Figure 5}
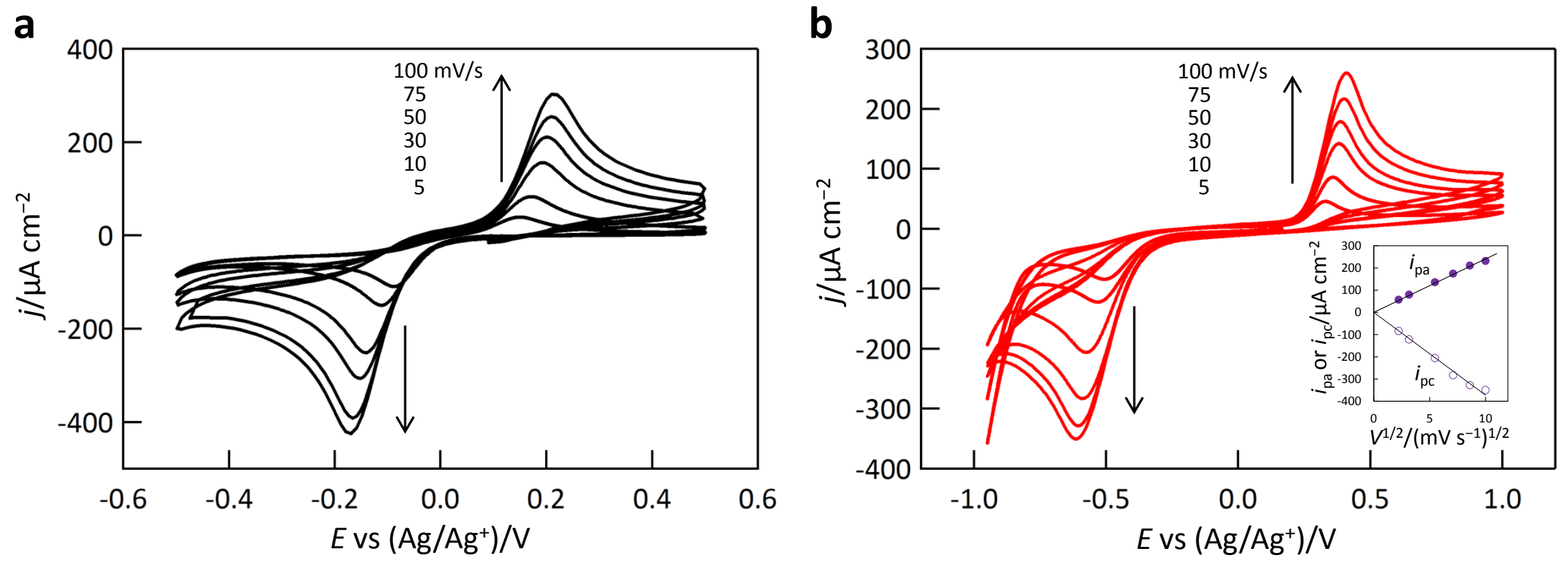


\section{T. Kondo et al., Figure 7}
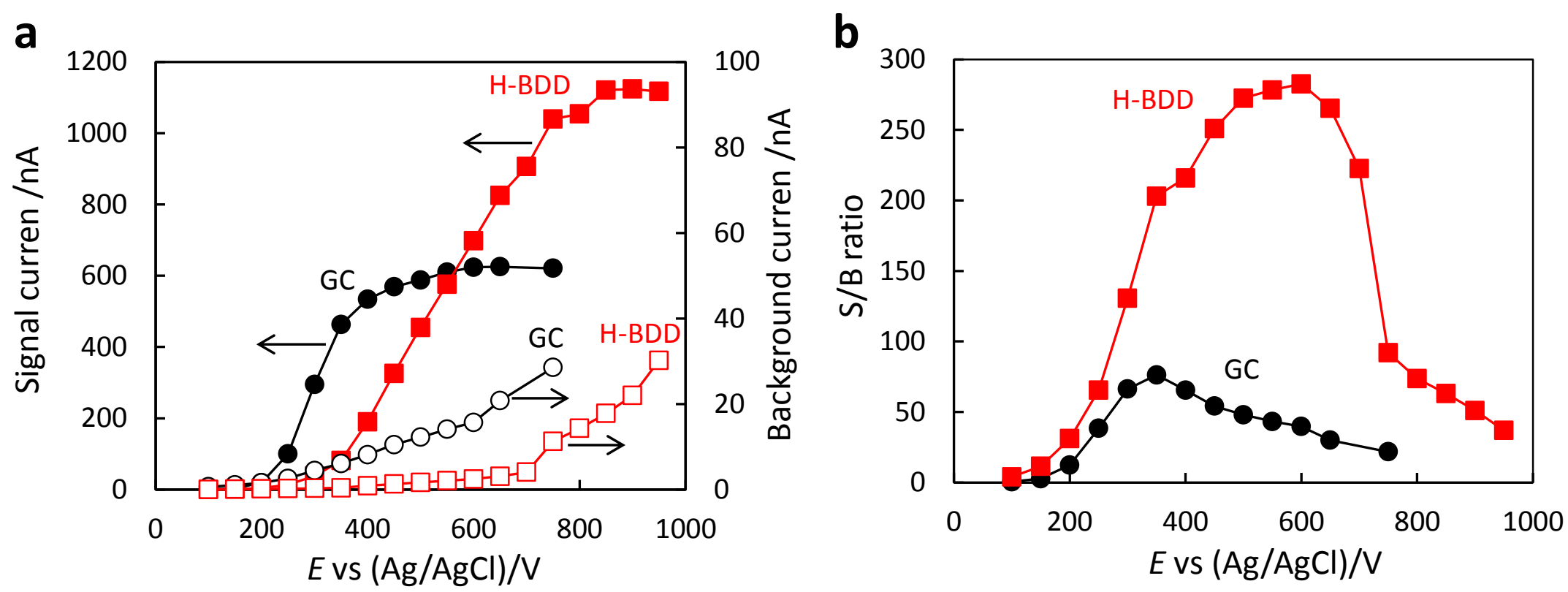


\section{T. Kondo et al., Figure 8}

a

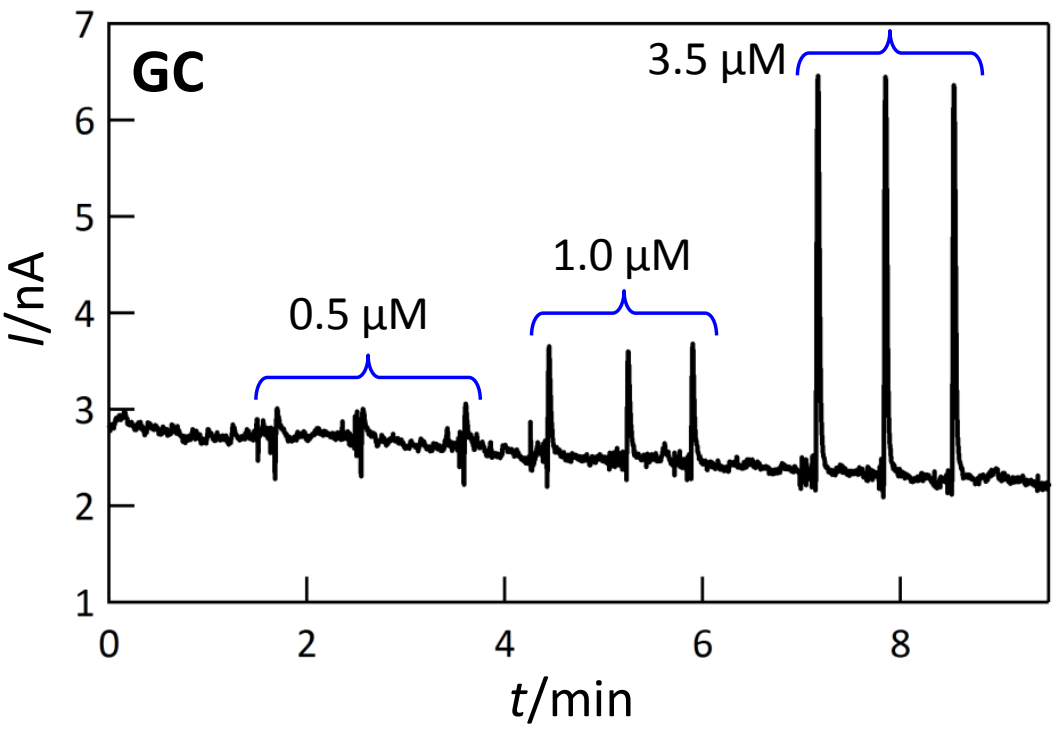

C

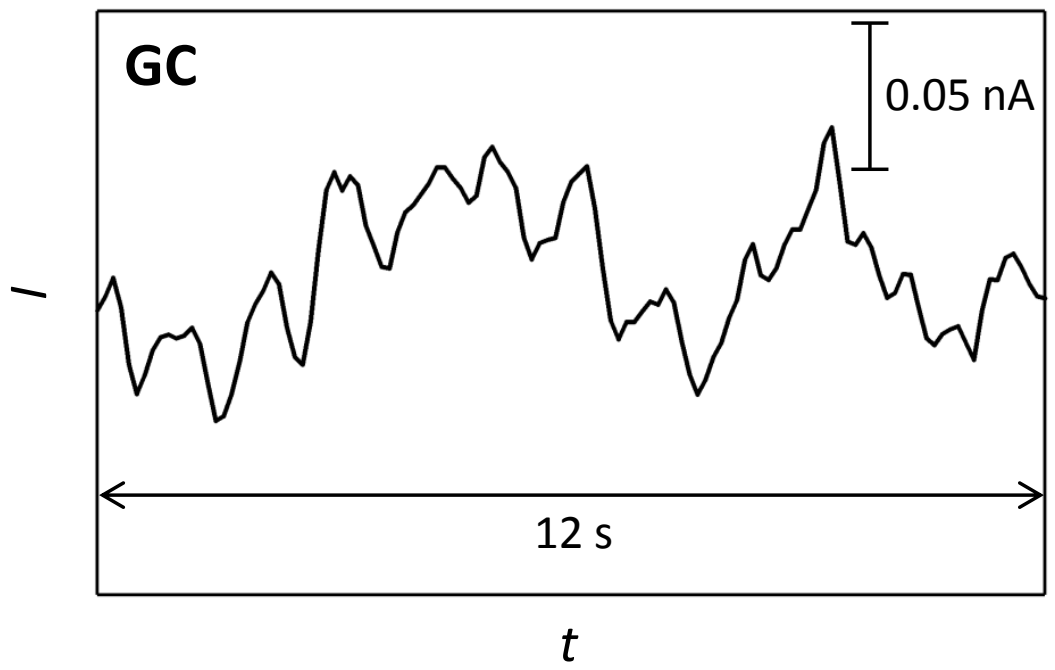

b

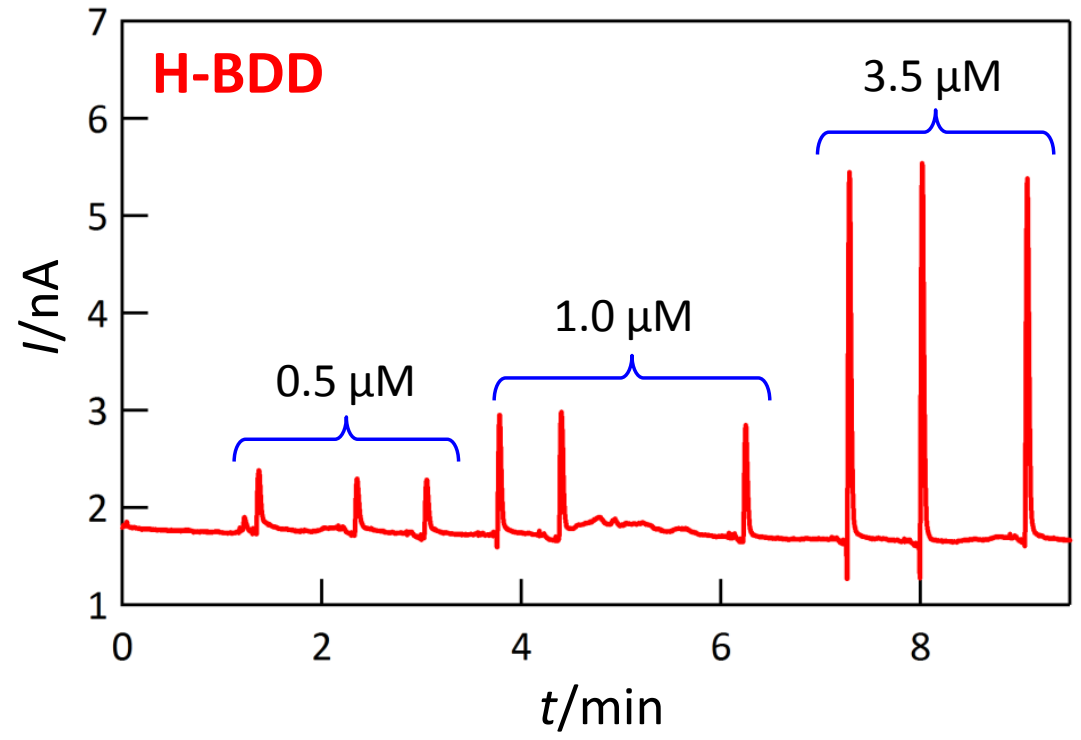

d

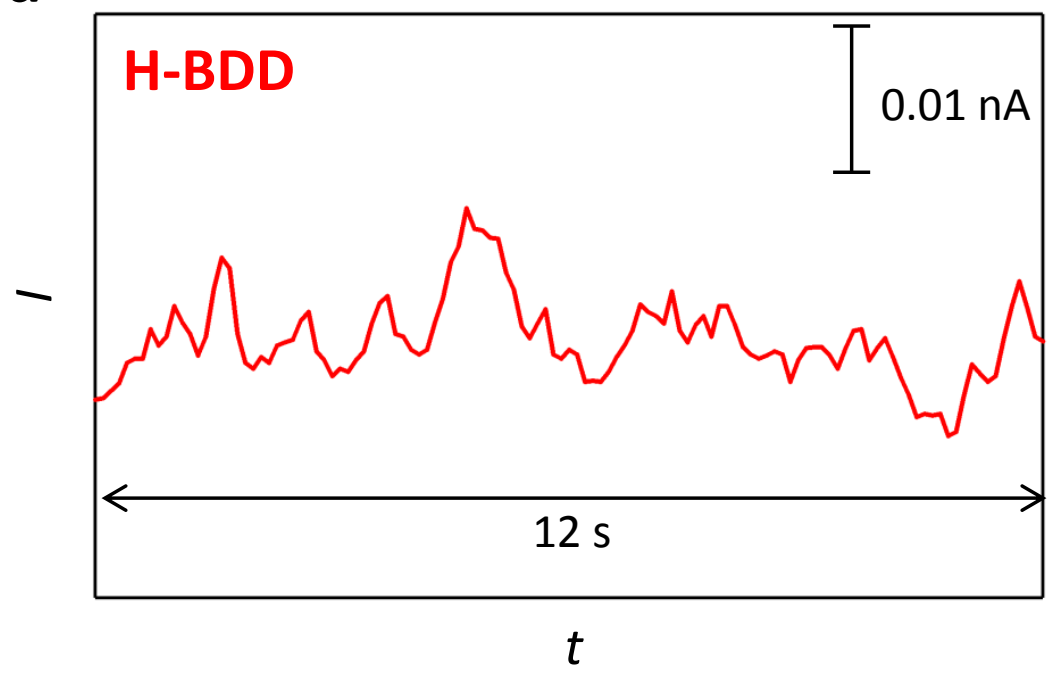




\section{T. Kondo et al., Figure 9}
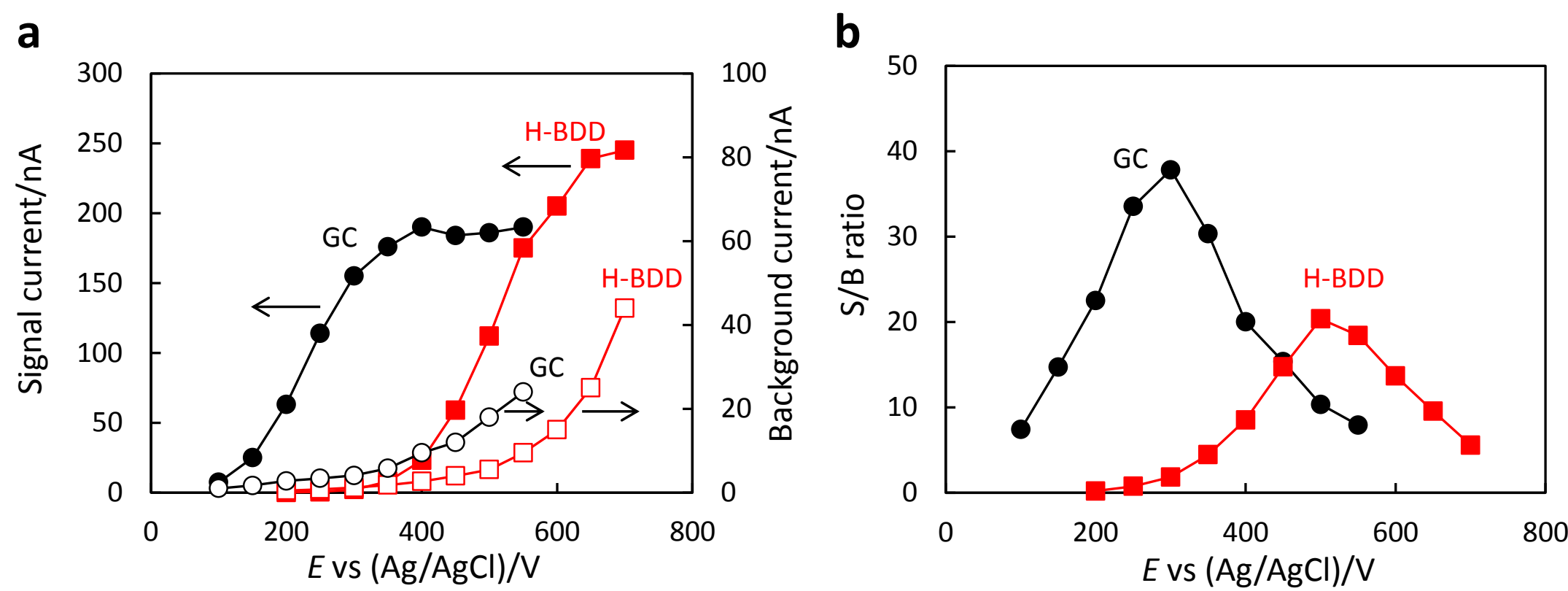